\title{
二状态的两参数齐次宽过去马氏过程 $*$
}

两参数宽过去马氏过程由其三点转移函 数族刻划. 为了研究过程的构造, 我们从只 有两个状态的状态空间 $E=\{0,1\}$ 开始. 我 们已求出了全部的二状态两参数齐次宽过去 马氏过程. 结果表明: 此类过程只有三种形 式, 即水平常值型、坚直常值型以及时间状 态对称型. 有关这些概念见文献 $[1 ３]$. 准 确地说, 我们得到下面的定理.

定理 二状态的两参数齐次可测三点转 移函数族 $\mathscr{P}=\left\{P_{i j k r}(s, t): i, j, k, r \in E=\{0\right.$, $1\}, s, t>0\}$ 必定是而且只能是下列 3 种形 式之一。

$$
P_{i j k r}(s, t)=\left\{\begin{array}{c}
1-\lambda\left(1-\mu^{\prime}\right), \text { 如果 } \\
i, j \in E, k=0, r=0, \\
\lambda\left(1-\mu^{2}\right), \text { 如果 } \\
i, j \in E, k=0, r=1, \\
(1-\lambda)\left(1-\mu^{2}\right), \text { 如果 } \\
i, j \in E, k=1, r=0, \\
1-(1-\lambda)\left(1-\mu^{2}\right), \text { 如果 } \\
i, j \in E, k=1, r=1,
\end{array}\right.
$$

其中常数 $\lambda, \mu \in[0,1]$. 上式右方与 $s>0$ 无 关,因而 $\mathscr{P}$ 是水平常值型的.

$$
P_{i j k r}(s, t)=\left\{\begin{array}{c}
1-\lambda\left(1-\mu^{s}\right), \text { 如果 } \\
i, k \in E, j=0, r=0, \\
\lambda\left(1-\mu^{s}\right), \text { 如果 }, \quad k \in=E, j=0, r=1, \\
(1-\lambda)\left(1-\mu^{s}\right), \text { 如果 } \\
i, k \in E, j=1, r=0, \\
\left(1-(1-\lambda)\left(1-\mu^{s}\right),\right. \text { 如果 } \\
i, k \in E, j=1, r=1,
\end{array}\right.
$$

其中常数 $\lambda, \mu \in[0,1]$. 上式右方与 $t>0$ 无 关,因而 $\mathscr{P}$ 是坚直常值型的.

$$
\begin{aligned}
& \text { (III) 对 } i, j, k, r \in E \text {, 有 } \\
& P_{i j k r}(s, t)=\frac{1}{2}\left[1+(-1)^{i-j-k+r} p^{s t}\right],
\end{aligned}
$$

其中常数 $p \in[0,1]$. 将上式中右方的 $s$ 与 $t$ 交换后, 或 $j$ 与 $k$ 交换后, 其值不变, 因而 $\mathscr{P}$ 是时间对称型的,也是状态对称型的.

\section{参考文献}

1 部军义, 杨向群. 两参数 Markov 链的三点转移函数 及其四个偏微分方程组. 中国科学, A 辑, 1992, (1): (1): $40 \sim 50$

2 杨向群, 李应求. 两参数马氏过程的若干新进展 (I). 湘罩大学自然科学学报, 1991, 13(2): 1 15

3 杨向群, 李应求. 两参数马氏过程的若干新进展 (II). 湘潭大学自然科学学报, 1991, 13(4): $43 \sim 52$

4 王梓坤. 生灭过程与马尔科夫链. 北京: 科学出版 社, 1980. 139

5 Korezliogu H, Lefort P. Une propriete Markovienne pour les processus á deux indics. Paris: C R Acad Sci. 1971, 273: $1071 \sim 107 \dot{4}$

\section{杨向群}

(汕头大学数学研究所, 汕头 515063 ; 湖南师范大学 数学系, 长沙 410081)

*国家自然科学基金和湖南省自然科学基金资助项目 